\title{
Retóricas de la curación
}

\section{Rhetorics of cure}

\author{
Alberto Lifshitz* \\ Universidad Nacional Autónoma de México, Facultad de Medicina, División de Estudios de Posgrado, Ciudad de México, México
}

Nadie cuestiona la supremacía de la prevención por sobre la atención médica dirigida a reparar un daño establecido. Los argumentos que sustentan esta ventaja son por lo menos de índole filosófica, económica y práctica. Es obvio que evitar la enfermedad es infinitamente más deseable que padecerla, ya no se diga experimentar sus complicaciones o secuelas. Prevenir es, sin duda, el propósito supremo de la medicina.

¿Cuál es entonces la cuestión, si todo confluye para enaltecer la prevención? El asunto que traba el camino es la factibilidad. Las condiciones para prevenir enfermedades incluyen el conocimiento de su historia natural y de las maniobras que la modifican efectivamente. El mayor éxito se ha tenido en las enfermedades infecciosas susceptibles de vacunación, algunas de las cuales han sido incluso erradicadas gracias a acciones médicas o sanitarias. Pero esta victoria no se ha podido generalizar hacia muchas de las enfermedades que azotan a las sociedades urbanas contemporáneas, como las enfermedades crónicas. Aunque sabemos algo de la influencia de los estilos de vida, ha sido muy difícil convencer y conseguir apegos. La extensión del concepto de prevención hacia la modificación de la historia natural en cualquiera de sus etapas lo que ha logrado es enfatizar la anticipación, la conveniencia de actuar antes de lo que lo solemos hacer. La prevención secundaria, terciaria y cuaternaria ponderan el valor de las tareas de anticipación, sin dejar de hacer honor a los argumentos filosóficos, económicos y prácticos de la medicina preventiva.

La factibilidad preventiva ha dejado, como ya se ha dicho, cuantiosas frustraciones que hoy por hoy sobrecargan las áreas de la llamada "medicina curativa", jerarquizada generalmente en un nivel más bajo que la prevención. Se critica que los servicios de salud son más bien de enfermedad, que la formación médica está centrada en el diagnóstico y tratamiento de las enfermedades establecidas, que las grandes inversiones en equipos y hospitales podrían moderarse haciendo énfasis en la prevención y que con ello evitaríamos también numerosos daños iatrogénicos.

Este escrito no pretende desacreditar este punto de vista, pero sí reconocer que no se ha alcanzado aún la perspectiva ideal de poder prescindir de la medicina curativa, aun cuando se le reconozcan ciertos inconvenientes. Se trata tan solo de entender el momento que enfrenta la profesión en que la atención de la enfermedad establecida supera los requerimientos de tareas profesionales por encima de la ansiada prevención. Llamarle medicina curativa puede ser un exceso, pero se ha adoptado por falta de un mejor adjetivo y por contrastarla con la medicina preventiva. Curar es sanar, recobrar la salud, eliminar la enfermedad, lo cual es ciertamente una aspiración, pero frecuentemente se tiene que limitar a logros menores. La enfermedad aguda suele ser curable, pero no así la crónica. De este modo, la medicina "curativa" se conforma con paliar, desacelerar, reducir las molestias, detener la progresión, controlar, adaptar al paciente a su enfermedad, retrasar la muerte y evitar complicaciones y secuelas. En suma, pretende curar, pero pocas veces lo logra en términos absolutos, aunque los beneficios intermedios no son menores. Si se intentara sustituir la designación de medicina curativa se pueden proponer otros términos, pero no 
resultan muy eufónicos o precisos: restaurativa, terapéutica, de atención al daño, sanativa, prescriptiva, restablecedora, hegemónica. En este escrito le seguiremos llamando curativa.

La medicina curativa y la preventiva no son suplementarias; por el contrario, son complementarias y no debieran confrontarse ni compararse puesto que son de naturaleza diferente. Ciertamente, la medicina curativa es reactiva y no siempre anticipatoria, más vinculada con la reparación que con el mantenimiento, más enfocada a responder a una demanda que a asumir una iniciativa. La expectativa de que la medicina preventiva vuelva obsoleta a la curativa tendrá que esperar mucho (si es que algún día lo hace). Todavía es inoportuna la propuesta de enfocar toda la formación médica hacia la prevención, lo cual sería válido si no se desprecia la atención de las enfermedades.

Pero curar no es solo restituir lo perdido. También es moderar y atenuar, y puede hacer referencia al proceso y no solo al desenlace: curar una herida es un procedimiento que puede durar varios días. Tal vez fuera preferible hablar de tratar la herida o de realizar curaciones más que de curar. Pero el origen del término curar (cura en latín) también significa cuidados (care en inglés), esmero, atención e, incluso, amor; de modo que armoniza con la filosofía de servicio de las profesiones de la salud. Aunque "sanar" (healing en inglés) se refiere como sinónimo de curar, para algunas personas es más un cambio espiritual que una restauración física.

Curar no siempre desemboca en la curación y ya se mencionaron algunos desenlaces intermedios. Curar la cruda o resaca pretende aliviar los síntomas, pero muchas veces perpetúa el alcoholismo (en Chile y Argentina se utiliza el término curar para embriagarse, emborracharse y hacer trampa en el juego). A veces una cura desemboca en secuelas o genera inconvenientes colaterales de ella misma.

El término "curar" se extiende hacia entidades inertes, cuando se trata de resolver algunos inconvenientes o prevenir algunas consecuencias. Se curan los defectos inherentes y se evitan otros cuando se cura un molcajete de piedra volcánica o una olla de barro, en tanto que con el procedimiento se sellan los poros. Los enseres de metal se curan antes de usarlos para eliminar residuos de fabricación; en el caso de los de hierro para impedir la oxidación. Se cura la carne y el pescado para conservarlos (salándolos, ahumándolos, secándolos), las hojas de tabaco para prepararlas, las pieles de animales muertos para comercializarlas, los hilos para blanquearlos. En México, se cura el pulque mezclándolo con diversas sustancias para modificar su sabor y suavizar sus efectos embriagantes. Se curan las parrillas de hierro, las rejillas de acero inoxidable y los sartenes de hierro fundido; se curan artefactos para deshacer hechizos, lo mismo que las barajas españolas, las cartas de lotería y las de póker; el bambú se acondiciona curándolo para hacer manualidades; la madera, para amasar, hacer rodillos y para picar; se curan los troncos y raíces de acuario, el jabón casero, los nopales antes de cocinarlos para quitarles la baba, los pepinos para quitarles lo amargo, los encurtidos, las piedras o placas de sal y distintas variedades de queso.

Curar es, pues, restaurar, sanar, restablecer, mejorar y aliviar. Es también secar, salar, curtir, restañar, acecinar y acondicionar. No puede ser que un término que significa tantas cosas y que ha contribuido más que otros muchos al desarrollo social sea despreciado o subordinado. La medicina curativa seguirá viva muchos años y la preparación de los médicos no puede marginarla, sin negar la prioridad de la prevención.

\section{Lecturas recomendadas}

1. Wang F. The roles of preventive and curative health care in economic development. PLoS One 2018;13:e0206808.

2. Lifshitz A. La medicina curativa y la medicina preventiva: alcances y limitaciones. Med Int Méx. 2014;30:64-72.

3. López-Moreno S. Salud pública y medicina curativa: objetos de estudio y fronteras disciplinarias. Salud Publica Mex. 2000;42:88-89. 